\title{
PRODUÇÃO DA BIBLIOTECA DIGITAL DO IBICT SOBRE INTERSECCIONALIDADE E SABERES DOCENTES
}

\author{
Fernando Guimarães Oliveira da Silva ${ }^{1}$ \\ https://orcid.org/0000-0002-5428-2870
}

RESUMO: Dialogar acerca do panorama da produção do conhecimento sobre o uso da interseccionalidade como parte dos saberes docente, nos bancos de dissertações e teses publicados na Biblioteca Digital do Instituto Brasileiro de Informação em Ciência e Tecnologia (IBICT), consolida-se foco do presente manuscrito. A abordagem do diálogo proposto centra-se nos estudos pós-críticos em educação por se propor relacionar diferenças e ato de ensinar. Utiliza-se, para isso, a pesquisa bibliográfica, especialmente o recurso do estado da arte, a partir da junção dos descritores: interseccionalidade e saberes docentes. Com estes dados, pretende-se levantar, tabular, periodizar e caracterizar as contribuições das dissertações e teses das áreas filtradas. Dos dados, conclui-se que são inovadores os diálogos da interseccionalidade como recurso metodológico promotor de práticas de ensino que reconheça as possibilidades de se alcançar contextos pedagógicos e curriculares preocupados com os direitos humanos, diferenças e a desconstrução de vias de subalternidades.

PALAVRAS-CHAVE: Estado da arte. Educação para diversidade. Processo de ensinoaprendizagem. Saberes do docente.

\section{THE PRODUCTION OF THE IBICT'S DIGITAL LIBRARY ON INTERSECTIONALITY AND TEACHING KNOWLEDGE}

ABSTRACT: The focus of this manuscript is to discuss the panorama of knowledge production about the use of intersectionality as part of teachers' knowledge in the dissertation and thesis databases published in the Digital Library of the Brazilian Institute of Information in Science and Technology (IBICT). The approach of the proposed dialogue is focused on post-critical studies in education by proposing to relate differences and the act of teaching. For this, the bibliographical research is used, especially the resource of the state of the art, from the combination of descriptors: intersectionality and teaching knowledge. With these data, we intend to survey, tabulate, periodize and characterize the contributions of dissertations and theses from the filtered areas. From the data, we conclude that it is innovative the dialogues of intersectionality as a methodological resource promoting teaching

1 Doutor pelo Programa de Pós-graduação em Educação da Universidade Estadual de Maringá (UEM, Sede). Professor do Programa de Pós-graduação em Educação da Universidade Estadual de Mato Grosso do Sul (UEMS), Unidade de Paranaíba/MS. fernando.oliveira@uems.br 
practices that recognize the possibilities of achieving pedagogical and curricular backgrounds concerned with human rights, differences and the deconstruction of paths of subalternities.

KEYWORDS: State of art. Education for diversity. Teaching-learning process. Teacher's knowledge.

\section{LA PRODUCCIÓN DE LA BIBLIOTECA DIGITAL DEL IBICT SOBRE INTERSECCIONALIDAD Y CONOCIMIENTO DOCENTE}

RESUMEN: El tema central de este manuscrito es el diálogo sobre el panorama de la producción de conocimiento sobre el uso de la interseccionalidad como parte del conocimiento docente en los bancos de disertaciones y tesis publicadas en la Biblioteca Digital del Instituto Brasileño de Información en Ciencia y Tecnología (IBICT). El enfoque del diálogo propuesto se centra en los estudios de educación poscrítica, ya que propone relacionar las diferencias y el acto de enseñar. Para esto, se utiliza la investigación bibliográfica, especialmente el recurso de vanguardia, basado en la combinación de descriptores: interseccionalidad y conocimiento de la enseñanza. Con estos datos, se pretende encuestar, tabular, periodizar y caracterizar las contribuciones de las disertaciones y tesis de las áreas filtradas. A partir de los datos, se concluye que es innovador los diálogos de interseccionalidad como un recurso metodológico que promueve prácticas de enseñanza que reconocen las posibilidades de alcanzar contextos pedagógicos y curriculares relacionados con los derechos humanos, las diferencias y la deconstrucción de formas subalternas.

PALABRAS CLAVE: Estado del arte. Educación para la diversidad. Proceso de enseñanzaaprendizaje. Conocimiento del maestro.

\section{Itinerários introdutórios}

O tratamento dado às linhas introdutórias do presente manuscrito vincula-se à ideia de itinerário. No dicionário Michaelis (2020), o conceito de itinerário comparece para descrevê-lo como adjetivo e substantivo. Em relação ao primeiro, caracteriza-se como relativo a caminhos e das medidas indicadoras da distância de um lugar a outro e, no segundo, refere-se à indicação de trajeto ou caminho a seguir: o respectivo percurso e um roteiro de viagem. Não importa a classe de palavras, observa-se que itinerário comparece para descrever um caminho percorrido. Com a compreensão de itinerário segundo 
Michaelis (2020) que importa descrever os caminhos percorridos para o entendimento da interseccionalidade como recurso pedagógico possível para o ato de ensinar em diferentes áreas dos saberes escolares.

Tomaz da Silva (2000, p. 75) reconhece que identidade e diferença são: a) mutuamente determinadas, b) articuladas e c) interdependentes; criou assim, elementos para afirmar que a diferença vem em primeiro lugar: "Para isso seria preciso considerar a diferença não simplesmente como resultado de um processo, mas como o processo mesmo pelo qual tanto a identidade quanto a diferença (compreendida, aqui, como resultado) são produzidas". Com essa consideração, Silva (2000) introduz a perspectiva dos processos de diferenciação. $O$ autor confirma também que a linguagem utiliza dos processos de diferenciação para criar os sujeitos normativos e os subversivos. A partir disso, o autor coloca preocupações para o ato de ensino e aprendizagem.

Significa reconhecer que estariam, professores/as, preocupados/ as com a formação de sujeitos iguais ou diferentes? No processo de ensino e aprendizagem, nota-se vetores de proliferação dos discursos normativos, caso o/a professor/a não opte por metodologias e práticas mais libertárias. No que se aplica tal afirmativa, vale problematizar o uso de recursos alternativos, contra hegemônicos e de transgressão para o ato de ensino e aprendizagem estrategicamente situado no enfrentamento da imposição de valores normativos e moralistas excludentes da história de grupos subalternos da cena do conteúdo escolar. Entende-se por grupos subalternos, aqueles/as que se situam assimetricamente em referência à norma de ser (negros/as, mulheres, deficientes, gays, lésbicas, travestis, transexuais, transgêneros...).

Importa reconhecer que a caminhada, neste itinerário, se faz em meio a um contexto societário de mudanças profundas que, na concepção de Vera Candau (2008), se referem também às transformações na época. No cerne das transformações, a autora diz que a problemática da igualdade e dos direitos humanos comparece como parte de um debate central: "[...] em um mundo marcado por uma globalização neoliberal excludente, e as questões da diferença e do multiculturalismo, em tempos de uma mundialização com pretensões monoculturais" (CANDAU, 2008, p. 45).

Candau (2008) afirma que a questão da igualdade seria central para entender toda a luta da modernidade pelos direitos humanos, porém, a autora considera relevante reconhecer que houve um deslocamento de interesse e a questão das diferenças passa a se localizar como um direito quando discutimos e debatemos educação. Interessa pontuar, a partir de estudos exploratórios e iniciais realizados por Candau (2008), sob o enfoque de Boaventura de Souza 
Santos, os núcleos agrupados para caracterizar a educação intercultural numa perspectiva crítica e emancipadora.

Uma educação intercultural que promova a articulação entre igualdade e diferença, parte, segundo a autora, de quatro núcleos: 1) a desconstrução de preconceitos, 2) a articulação igualdade e diferença, 3) resgate dos processos de construção das identidades culturais e, por fim, 4) promover experiências sistemáticas de interação com as outras pessoas. Candau (2008) reconhece que o uso dessa proposta de educação intercultural se propõe como uma alternativa contra hegemônica aos processos de normatização social que interpela as pessoas a assumirem práticas sociais, culturais e econômicas unívocas.

A proposta deste artigo é apresentar apontamentos iniciais de um projeto de pesquisa, Contribuições da interseccionalidade com as diferenças para se problematizar o saber-fazer docente (2019-2021), desenvolvido junto à Universidade Estadual de Mato Grosso do Sul (UEMS). Explorou-se, para este fim, o recurso do estado da arte proposto pela pesquisa bibliográfica para cartografar um panorama da produção do conhecimento em uma plataforma de dissertações e teses, a Biblioteca Digital do Instituto Brasileiro de Informação em Ciência e Tecnologia (BDTD/IBICT). Nela, filtraram-se as pesquisas no campo dos Colégios de Ciências Humanas, Linguística, Letras e Artes e Ciências Sociais Aplicadas, conforme propõe o Centro de Aperfeiçoamento de Pessoal de Ensino Superior (CAPES), e que estiveram registradas a partir dos seguintes descritores: interseccionalidade e saberes docentes.

No que se refere à abordagem, focou-se nos estudos pós-críticos em educação, por se tratar do uso de uma ferramenta teórico-metodológica como recurso de ensino e aprendizagem que parte do envolvimento com temáticas que representam demandas de opressão, organização cultural e reivindicações de grupos minoritários, especialmente mulheres negras como se verá nas linhas posteriores à introdução. Com o resultado do filtro de dados da plataforma IBICT, pretende-se levantar, tabular, periodizar e caracterizar as contribuiç̧̃es das dissertações e teses das áreas filtradas.

No escopo da proposta, propõe-se produzir, num primeiro momento, diálogos e conversações com enfoque foucaultiano da arqueologia do saber, para compreender o cenário de produção acadêmica sobre o uso da interseccionalidade como um recurso metodológico e de práticas de ensino, o qual se estrutura o texto da seguinte maneira: 1) Método; 2) Conceitos em saberes docentes; 3) Saberes sob enfoque da interseccionalidade; 4) Análise e interpretação dos dados tabulados no IBICT. 


\title{
Método
}

Com o objetivo de discutir os efeitos das teorias pós-críticas no cenário da pesquisa em educação no Brasil, Marlucy Paraíso (2004) esboçou um mapa, no período entre 1993 e 2003, de ensaios e pesquisas divulgadas nos encontros anuais da Associação Nacional de Pós-graduação e Pesquisa em Educação (ANPED). Evidenciou o caráter experimental e explícito de uma variedade de linguagens e autorias de pensamentos teóricos que abordagem, sob o enfoque das teorias pós-críticas, as práticas pedagógicas e curriculares abertas à transgressão, à subversão e às diferenças:

\begin{abstract}
Usando uma linguagem que recebe influências da chamada "filosofia da diferença”, do pós-estruturalismo, do pós-modernismo, da teoria queer, dos estudos feministas e de gênero, dos estudos multiculturalistas, pós-colonialistas, étnicos, ecológicos etc., as teorias pós-críticas realizam, no campo educacional brasileiro, substituições, rupturas e mudanças de ênfases em relação às pesquisas críticas (PARAÍsO, 2004, p. 284).
\end{abstract}

Como se vê, a temática que se pretende abordar - interseccionalidade e diferenças -, encontra-se no campo teórico das perspectivas pós-criticas em educação. É possível compreender que são feitas requisições de práticas pedagógicas e curriculares que acontecem no contexto de uma instituição, a escola, que pode cuidar de reproduzir corpos e existências normativas no contexto dos padrões eurocêntricos. Estes, no caso, criam um universo de referência com cor, raça, etnia, cultura que notabilizam o exercício de poder.

Com a força que tais padrões refletem sobre a condição humana, pode a escola ser um local que contribui para sua manutenção. O uso de autorias teóricas que caminham no contexto das teorias pós-críticas é que justificam a necessidade de desconstrução com os padrões eurocêntricos impostos. Parte-se, então, de concepções inventivas e que provocam rupturas dos padrões, a presente abordagem: "[...] não gostam de explicações universais, nem de totalidades, nem de completudes ou plenitudes" (PARAISO, 2004, p. 286).

Em Sandra Corazza (2001), por sua vez, a pesquisa em educação, quando se debruça sob o olhar pós-crítico, visa buscar um saber sobre um assunto que ainda não se havia dito ou se ousava dizer no ambiente escolar. Simboliza, então, o que se pretende com o estudo, uma vez que diferentes sistemas de opressões que afetam as minorias sociais podem não ser cotidianamente debatidas pelas diferentes áreas do saber na escola. 
Corazza (2001) destaca que esse enfoque de pesquisa busca problematizar o que não é dito, aquilo que é esquecido, porque não há redes de significação que se propõem a enunciar sobre o que não é permitido e autorizado dizer. A questão de um sujeito diferente que apresenta novíssimas demandas, por exemplo, representa esse campo do não dito e do irreconhecível. Consequentemente, para a autora, a pesquisa pós-crítica

\begin{abstract}
implode com o sistema consensual das formas em que habitualmente compreendemos, falamos e escutamos uma linguagem curricular. Implosão de sentidos que, no mínimo, faz "saltar" o que estava ainda "não significado", o que era a-significante. Com sua principal tarefa política, a pesquisa pós-crítica quer transformar o funcionamento da linguagem de um currículo, na direção de modificar as suas condições de enunciação, fornecendo-lhes planos infinitos de possíveis (CORAZZA, 2001, p. 20).
\end{abstract}

$\mathrm{O}$ ato de ensino e aprendizagem se faz na relação ou interação entre os interlocutores que se produzem nos contextos de articulação das identidades e das diferenças. Nesse sentido, não se pode vivenciar, nessa interação, um processo de sobreposição cultural, mas a sua articulação e diálogos para evitar apagamentos, eliminações e inverdades que tanto colonizaram a experiência histórica, cultural e política do Brasil.

Corazza (2001) amplia o seu entendimento das teorias pós-críticas como um recurso não tão somente interpretativo das pesquisas em educação, mas também do cotidiano escolar, da existência da escola enquanto uma instituição disciplinar e, também, da dimensão dos saberes que estão presentes no ato de ensino e aprendizagem como produtores-formadores de sujeitos eurocêntricos. Considera-se, nesse sentido, a amplitude do entendimento da autora, que se pretende investigar o panorama da produção acadêmica brasileira que produza rupturas com quadros epistemológicos eurocêntricos e colonizadores.

Além disso, o que as pesquisas dos programas brasileiros de pós-graduação nas áreas de ciências humanas, linguística, letras e artes e sociais aplicadas realizam como possibilidades de rupturas com o pensamento colonial que encabeça o uso de saberes e práticas de ensino em diferentes áreas do conhecimento e conteúdo escolar eleito. Para isso, elegeu-se um conjunto de teorias que caminham no campo das teorias pós-críticas que aferem possibilidades ao ato de ensino e aprendizagem preocupado com os estudos das diferenças baseados na perspectiva dos direitos humanos. 
Entende-se que o uso da pesquisa bibliográfica não é realizado de forma desconexa, mesmo que o estudo faça o uso apenas de referenciais teóricos, é preciso criar elementos que justifiquem a abordagem investigativa em curso. Telma da Silva e Regina Miotto (2007) destacam, à perspectiva do método dialético, que a pesquisa bibliográfica é um procedimento metodológico que implica o uso de procedimentos ordenados que buscam soluções pertinentes ao campo do objeto de estudo, levando o/a pesquisador/a a estar atento/a às suas expressões.

Lima e Miotto (2007) caracterizam procedimentos que devem ser considerados no uso da pesquisa bibliográfica:

Como a pesquisa bibliográfica tem sido um procedimento bastante utilizado nos trabalhos de caráter exploratório-descritivo, reafirma-se a importância de definir e de expor com clareza o método e os procedimentos metodológicos (tipo de pesquisa, universo delimitado, instrumento de coleta de dados) que envolverão a sua execução, detalhando as fontes, de modo a apresentar as lentes que guiaram todo o processo de investigação e de análise da proposta (LIMA; MIOTTO 2007, p. 39).

Visando dar prosseguimento ao uso da pesquisa bibliográfica, utilizou-se, como estratégia de coleta de dados, o estado da arte. De acordo com Norma Ferreira (2002), o estado da arte consiste no uso da pesquisa bibliográfica para caracterizar ou realizar um panorama da produção acadêmica de uma área ou objeto de estudo. Geralmente, o estado da arte é realizado em plataformas de pesquisas, em bancos de dissertações e teses, anais de eventos na área em debate, e periódicos acadêmicos, a partir de elementos que descrevam o objeto de estudo.

Joana Romanowski e Romilda Ens (2006) entendem que o estado da arte propicia a um/a pesquisador/a acompanhar as transformações que afetam o seu objeto de estudo ao longo de um período ou de uma época. Além disso, propõe acessar os aportes teóricos e práticos de determinada área do conhecimento, apontando as restrições, desafios e avanços, contribuindo assim para: "[...] identificar experiências inovadoras investigadas que apontem alternativas de solução para os problemas da prática e reconhecer as contribuições da pesquisa na constituição de propostas na área focalizada" (ROMANOWSKI; ENS, 2006, p. 39).

Como o objetivo do presente manuscrito é criar um panorama das pesquisas que envolvam interseccionalidade e os saberes docentes contidos 
em metodologias e práticas de ensino, observa-se que o uso do estado da arte propõe conhecer esse terreno e produzir estratégias de inovação. Diante disso, pretende-se colher os dados na plataforma de bancos e teses da Biblioteca digital do IBICT em diferentes áreas do saber.

Após colhidas as dissertações e teses, tabulou-se os dados com as seguintes informações: ano de publicação; Instituição de Ensino Superior (IES) de defesa; grau (D para dissertação e T para tese); a grande área dos colégios de Humanidades, Ciências sociais e Linguística, letras e artes e a autoria.

\section{Conceitos em saberes docentes}

Não interessa trazer questões no âmbito da didática ou de perspectivas teóricas sobre a aprendizagem. Convém problematizar a questão da relação ensino e aprendizagem a partir de elementos teórico-metodológicos para que professores/as possam se preocupar com a dimensão dos recursos pedagógicos que utilizam. Então, observa-se mais produtivo tratar a questão dos métodos, recursos, técnicas e instrumentos pedagógicos no contexto dos saberes docentes acionados para o ensino e aprendizagem.

Nas primeiras palavras da obra Pedagogia da autonomia, Paulo Freire (1996) reconhece que o ato de formar vai além do treinar. Trata-se de compreender que a ética é uma marca da natureza humana, o que na concepção de Freire (1996) reflete também na prática educativa. A ética definida refere-se à perspectiva de que o puritanismo e a pureza são criações moralistas que não dá espaço ao diferente.

Freire (1996) confirma não haver docência sem discência. Com tal afirmativa, o autor se permite questionar em que peso as práticas sociais produzem conhecimentos que merecem estar em pauta nos conteúdos escolares. A prática educativa, pela via da natureza ética, se responsabiliza por formar o estudante para a vida social.

\footnotetext{
É preciso, sobretudo, e aí já vai um destes saberes indispensáveis, que o formando, desde o princípio mesmo de sua experiência formadora, assumindo-se como sujeito também da produção do saber, se convença definitivamente de que ensinar não é transferir conhecimento, mas criar as possibilidades para a sua produção ou a sua construção (FREIRE, 1996, p. 22).
}

O/a estudante vive o que Freire (1996) caracteriza como uma curiosidade epistemológica. A presente afirmativa traz para o ato de ensinar a adoção 
de saberes e práticas de ensino preocupadas com a produção de rupturas com a educação bancária. Evidentemente, o ato docente precisa partir de problematizações criativas acerca de aspectos históricos, sociais, econômicos, culturais... que permeiam a condição existencial dos/das alunos/as com o objetivo principal de formar e não de alienar.

A ideia é que os saberes e práticas de ensino tenham relação com o universo de referência dos/das estudantes, oportunizando o que o Freire (1996) caracteriza como um conteúdo escolar engajado no campo de vida. No tempo presente, encontram-se aspectos identitários, culturais, e históricos de diferentes grupos, que secularmente foram apagadas por conta de uma autoridade moral religiosa e eurocêntrica.

A proposta, aqui pretendida, é debater sobre o uso de saberes em práticas de ensino focadas no universo de referência de pessoas negras, homossexuais, travestis, transexuais, trabalhadoras domésticas e outros grupos. Ao trazer a perspectiva de Freire (1996), indica-se caminhos oportunos para se pensar a prática docente engajada na luta contra sistemas de opressões naturalizados na história do Brasil.

Para Célia Borges (2001), no início da década anterior, apontou que as pesquisas sobre os saberes docentes se expandiram significativamente. Segundo o que a autora enfatizou, a maior parte dos estudos efetivaram-se sob o viés de um campo teórico-metodológico bem diversificado e eclético. Objetivando caracterizar tal diversidade deste campo de estudos, Borges (2001) utilizou de três referenciais norte-americanos para sustentar a amplitude do campo dos saberes docentes, sendo: Lee Schulman, Daniel Martin e Gauthier.

Emaranhando-se nos estudos de Schulman (1986 apud, BORGES, 2001), a autora destaca que os estudos sobre saberes docentes começaram a despontar relevantes na década de 80 . Os pontos norteadores dos estudos nesse campo, na concepção de Borges (2001, p. 61), aconteceram por conta do descontentamento com a educação norte-americana e a má formação de professores/as: "Trata-se, portanto, de uma personalidade que tem influenciado não apenas o meio científico acadêmico, mas também o meio político educacional".

Em segundo momento, Borges (2001) considera as pesquisas de Daniel Martin, porém sem muita repercussão como a de Schulman. Por outro lado, possui sua relevância por pontuar um atipologia das pesquisas acerca dos saberes docentes. O mesmo objetivo de Martin foi proposto por Gauthier, conforme destaca a autora: 
Estes autores também estão preocupados com a natureza dos saberes, mas a ideia central que os alimenta é mais ambiciosa. Eles pretendem dar conta do problema relativo a um repertório de conhecimentos, presente nas pesquisas sobre o knowledge base, assumindo uma posição de crítica às abordagens desenvolvidas pelos pesquisadores americanos. $O$ contexto de sua obra é o de internacionalização das reformas do ensino e da formação dos professores, e da explosão da problemáticas saberes, ela própria (BORGES, 2001, p. 62).

De acordo com Borges (2001), as pesquisas de Martin e Gauthier possuem sua relevância, mas a de Schulman, sem dúvidas, causou e provocou maiores protagonismos no corpus teórico acerca da temática dos saberes docentes. Isso se deve porque o autor avançou no campo de estudos eleitos para sua análise, mapeando abordagens, perspectivas e lacunas. Com o produto da análise de Borges (2001), pode-se pontuar que Schulman mapeou abordagens gerais; Martin, a pluralidade teórico-metodológica, e Gauthier et al descreve o repertório de saberes subjacentes ao ato de ensinar.

Em pesquisa paralela, Célia Nunes (2001) realizou um panorama sobre saberes docentes e a formação de professores. Assim como Borges (2001) bem apresentou, Nunes (2001) também caracteriza a temática urgente e necessária na década de 80 e 90 . No contexto brasileiro, por sua vez, Nunes (2001, p. 28) pondera que nos anos 90 os estudos apareceram de forma tímida, nitidamente sob orientações teóricas norte-americanas, e considerou

[...] a complexidade da prática pedagógica e dos saberes docentes, buscam resgatar o papel do professor, destacando a importância de se pensar a formação numa abordagem que vá além da acadêmica, envolvendo o desenvolvimento pessoal, profissional e organizacional da profissão docente.

Informa Nunes (2001) que os estudos começam a realizar uma virada que passam a dar relevância aos saberes construídos pelos/as professores/as. É observado que esse reconhecimento se dá pela preocupação política, ideológica e social que a ação docente tem no processo de formação educacional dos/das educandos/as. Nunes (2001) confere temporalidade à questão dos saberes, dado que reconhece que eles aparecem com outras roupagens por considerar demandas da produção/reprodução de práticas pedagógicas e formativas.

Nunes (2001) parte dos estudos de Maurice Tardif para enfatizar a primazia do saber da experiência para entender a constituição da profissionali- 
dade do sujeito-professor/a. Para caracterizar a ênfase no saber da experiência, a autora destaca algumas características específicas do saber docente que a torna diferente de outras profissões.

\begin{abstract}
a) é especializado e formalizado; b) é adquirido na maioria das vezes na universidade, que prevê um título; c) é pragmático, voltado para a solução de problemas; d) é destinado a um grupo que de forma competente poderá fazer uso deles; e) é avaliado e autogerido pelo grupo de pares; f) requer improvisação e adaptação a situações novas num processo de reflexão; g) exige uma formação contínua para acompanhar sua evolução; h) sua utilização é de responsabilidade do próprio profissional (TARDIF, 1999 apud NUNES, 2001, p. 33)
\end{abstract}

Tal afirmativa remete aos estudos de Tardif (2002) para entender em que dimensão os conhecimentos acima citados conferem inteligibilidade à prática docente. $\mathrm{O}$ autor propõe que os saberes docentes são construídos continuamente e de forma progressiva. O/a docente realiza o processo de pensar sobre o como ensinar e o executa dessa forma, logo, há um processo de inclusão e domínio de saberes que, para Tardif (2002), são compreendidos como plurais.

Na concepção do autor, é possível classificar os saberes docentes sob o enfoque de quatro tipos: a) o saber da formação profissional, b) os saberes disciplinares, c) saberes curriculares e d) saberes experienciais; sendo que o último ocupa uma posição significativa na condução dos demais saberes. 0 autor aponta que os outros saberes são colocados no exercício da experiência docente, por isso adquire significado para o saber-fazer docente.

Observa-se que os saberes se relacionam com o uso de recursos potencializadores do ensino e da aprendizagem, principalmente porque sinaliza a adoção de métodos e técnicas, domínio de conhecimentos, apropriação e tratamento de informações à forma como se demanda o conteúdo escolar e a experiência de rotina e organização escolar. Segundo Tardif (2002), a confluência desse conjunto de elementos dá forma ao saber profissionalizado dos/das professores/as, legitimando o fazer da profissão.

Para esmiuçar as perspectivas que decorrem sobre a questão dos saberes docentes, Dermeval Saviani (1996) destacou que os saberes construídos pelos/as professores/as no processo de formação inicial e continuada relacionam-se à complexidade que é a educação, por conseguinte, o trabalho educativo também o é. Na caracterização dos saberes, o autor destaca cinco: a) os saberes atitudinais; b) os saberes crítico-conceituais; c) os saberes específicos da área; d) os saberes pedagógicos e e) os saberes didático-curriculares. 
Com estes saberes, Saviani (1996) compreende que o/a professor/a possui sua visão de mundo que define a concepção de educação e de ensino que ele/ela tem. No cruzamento com o ato de ensino e aprendizagem, tais concepções, que determinam os saberes, serão mobilizadas para ensinar e aprender. Diferentemente dos/das demais autores/as (BORGES, 2001; NUNES, 2001; TARDIF, 2002), Saviani (1996) não confere aos saberes da experiência a centralidade dos saberes necessários ao ato de ensinar.

Ao destacar diferentes perspectivas para entender a questão da produção de saberes docentes, aborda-se, neste estudo, a concepção de Tardif (2002), especialmente porque os saberes dos/das professores/as não são ligados a espasmos mentais desorientados, mas possuem relação com uma situação de ensino e aprendizagem derivada de diferentes momentos de sua vida (rodas de amigos, discussão teórica em grupos de pesquisa, debate com colegas de trabalho...) que caracteriza "[...] um saber ancorado numa tarefa complexa (ensinar), situado num espaço de trabalho (a sala de aula, a escola), enraizado numa instituição e numa sociedade" (TARDIF, 2002, p. 15).

Com tal consideração, acredita-se que o uso da interseccionalidade é uma ferramenta que pode auxiliar o/a professor/a a se aprofundar em questões sociais de opressão de alguns grupos que são caras à sociedade brasileira. Assim, trata-se de uma temática que traz preocupações para o modo como os sistemas de opressão são visualizados por frentes conservadoras que acreditam que tais discussões não são necessárias, porque colocam sob a ótica do privilégio certos grupos em detrimento de outros.

Para caracterizar a emergência do debate que se pretende encampar no próximo item, é válido destacar o seguinte acontecimento: na segunda quinzena do mês de maio, o Ministro do Supremo Tribunal Federal (STF) autorizou a divulgação de reunião ministerial ocorrida, em 22 de abril de 2020, no Palácio do Planalto, em Brasília. A divulgação da reunião se fez necessária, porque o ex-ministro da Justiça e Segurança Pública, Sérgio Moro, afirma que, na presente reunião, o Presidente Jair Bolsonaro tentou interferir nas investigações da Polícia Federal (PF). Com o presente acontecimento, encara-se, como Freire (1996) destacou, que em sala de aula, desassociar-se do senso comum, aguçar a curiosidade em direção à sua forma mais metodicamente rigorosa que é a curiosidade epistemológica sobre/no/para o real.

Não é o acontecimento que choca, mas a fala do atual Ministro da Educação, Abraham Weintraub, após a apresentação da Ministra da Mulher, Direitos Humanos e Família, Damares Alves, afirmar que, no nosso país, não existem dados sobre povos tradicionais e que salta aos olhos que o seu ministério descobriu que há 1.300 .000 (um milhão e trezentos mil) ucranianos com a cultura preservada e não havia dados sobre isso. Na fala da Ministra, nota-se 
que o uso da diferença é acionado para caracterização da variedade de públicos atendidos pela sua pasta: ciganos, indígenas, pessoas idosas, mulheres vítimas de violência, seringueiros... Muitos problemas de várias ordens atingem esses públicos, mas a preocupação maior da Ministra é atuar significativamente no fortalecimento de valores pró-vida e pró-família, segundo, obviamente, a sua concepção e não a concepção plural que paira no contexto das constituições familiares de diferentes grupos sociais.

Weintraub, por sua vez, deslegitima a produção cultural de alguns povos que compõem, o que por ele é entendido como "o povo brasileiro" e diz ser o único Ministro que está com processos no Comitê de ética da Presidência da República, e ainda traz:

1) o Governo está conversando com quem ele deveria lutar,

2) não está sendo duro contra os privilégios.

E adiciona

Odeio o Partido Comunista. Ele está querendo transformar a gente numa colônia. Odeio o termo "povos indígenas", odeio esse termo. Odeio. Os "povos ciganos". Odeio! Só tem um povo, nesse país, quem quer, quer e quem não quer, segue de ré. Só tem um povo, pode ser preto, pode ser branco, pode ser japonês, pode ser descendente de indígena, mas tem que ser brasileiro. Acabar com esse negócio de povos e privilégios. Só pode ter um povo, não pode ter Ministro que acha que é melhor que o povo, que o cidadão. Isso é um absurdo! [...] A gente veio aqui para acabar com tudo isso, não para manter essa estrutura (YOUTUBE, 2020, s./p.).

A ideia de trazer as falas da gerente da pasta dos direitos humanos e do gerente da Educação assinala a preocupação que paira sobre a preservação de cultura, da vida e de práticas sociais ligadas a alguns povos no nosso país. Trata-se de falas de apagamentos deliberados a favor de um patriotismo que desconsidera as diferenças presentes na concepção de "povo brasileiro". Ambos, Weintraub e Damares, estão em pastas que atuam significativamente com a diferença. A visão de legitimação identitária de um povo único e a concepção de atuar nos valores pode despregar a condição de cidadania de muitas pessoas diferentes e precarizar o atendimento de políticas públicas direcionadas à valorização dos povos diferentes.

Como se vê, os discursos proferidos na presente reunião ministerial afetam significativamente a educação e os direitos humanos, sobretudo a confluência entre estes dois assuntos. Intensifica, por um lado, a autorização da política do ódio tão presente no âmbito do atual governo e, por outro, des- 
qualifica e deslegitima a produção da diferença que permeia muitos povos que constituíram, ancestralmente, e constituem, na atualidade, a história brasileira. Evidentemente, traz para a discussão a necessidade do debate, primando pelo uso da interseccionalidade como uma forma de questionar, dar visibilidade e construir vias de superação aos instrumentos efetivamente discursivos e de poder que insistem em apagar a produção social das diferenças (SILVA, 2000).

\section{Saberes da interseccionalidade}

Disparou-se, no item anterior, os discursos pertencentes ao atual governo para dar emergência às discussões sobre a interseccionalidade como um recurso para as práticas (métodos e técnicas de ensino e aprendizagem) de professores/as. Dentre as questões problemáticas citadas pelos ministros, destaca-se: a) a ideia de privilégios e b) a superioridade da concepção única de povo brasileiro. Em ambas questões, é visível que não deveríamos ser tratados/as de acordo com nossas diferenças, mas sim, como o povo brasileiro, estabelecendo o limite da identidade como a referência única de atuação do atual Governo.

O que se pretende é partir da ideia de diferença e, para isso, a concepção subjacente à supremacia de "povo brasileiro" como uma identidade única e permanente não pode produzir invisibilidade para outros povos. Entender as diferenças permite, sob a ótica da interseccionalidade, compreender como uma avenida identitária negra, por exemplo, cruza com a concepção de povo brasileiro. A ideia de "povo brasileiro" possui, em seu interior, diferenças que se cruzam na constituição do que venha a ser esse grupo.

Emerge o debate sobre interseccionalidade, visto que se trata de uma metodologia interessante para se analisar o cruzamento de avenidas identitárias. Kimberlé Creenshaw (2002) elaborou um documento para o encontro de especialistas em aspectos da discriminação racial relativas ao gênero. A autora se viu frente à dificuldade de criar um argumento capaz de considerar as interações entre discriminações diversas que atingiam mulheres.

O conceito de interseccionalidade, na concepção de Kreenshaw (2002), faz parte do reconhecimento de que mulheres negras vivenciam vulnerabilidades decorrentes da interação e cruzamento das discriminações de raça e gênero. Conferir nome a essa interação faz emergir um problema e, sobretudo, a sua existência. Demanda assim, que se amplie a proteção pela via dos direitos humanos, dando atenção "[...] às várias formas pelas quais o gênero intersecta-se com uma gama de outras identidades e ao modo pelo qual 
essas intersecções contribuem para vulnerabilidade particular de diferentes grupos de mulheres" (CREENSHAW, 2002, p. 174).

Na necessidade de um conceito, Creenshaw (2002) propõe:

A interseccionalidade é uma conceituação do problema que busca capturar as consequências estruturas e dinâmicas da interação entre dois ou mais eixos da subordinação. Ela trata especificamente da forma pela qual o racismo, o patriarcalismo, a opressão de classe e outros sistemas discriminatórios criam desigualdades básicas que estruturam as posições relativas de mulheres, raças, etnias, classes e outras. Além disso, a interseccionalidade trata da forma como ações e políticas específicas geram opressões que fluem ao longo de tais eixos, constituindo aspectos dinâmicos ou ativos do desempoderamento (CREENSHAW, 2002, p. 177).

De modo enfático, a interseccionalidade propõe entender como se cruzam diferentes eixos de discriminação. O uso realizado por Creenshaw (2002), no presente documento, interpreta a questão interseccional como: metáfora, categorias de articulação e metodologia. Para Adriana Piscitelli (2008), o termo interseccionalidade se refere a teorizações sobre a multiplicidade de diferenciações sociais articuladas a gênero e, no campo dos estudos feministas, à proposta da interseccionalidade ou categorias de articulação "[...] é oferecer ferramentas analíticas para apreender a articulação de múltiplas diferenças e desigualdades" (PISCITELLI, 2008, p. 266).

Neste texto, compartilha-se da concepção de que a perspectiva teórica da interseccionalidade foi pensada por mulheres negras em suas reivindicações no interior do feminismo branco, e também do próprio movimento negro que produzia endosso às pautas dos homens e invisibilidade das mulheres negras.

Carla Akotirene (2019) compõe a quarta publicação da série Feminismo Plurais, de Djamila Ribeiro. Com a sua obra, Interseccionalidade, Akotirene (2019) se desafia na cientificidade do conceito como parte de uma manifestação não somente acadêmica, mas política de ancestralidade que elimina qualquer sombra que pretende esconder a riqueza do pensamento feminista negro.

Akotirene (2019) demonstra que abordar o conceito pressupõe a rejeição de expectativas elitistas, jargões acadêmicos, escrita complexa na terceira pessoa e abstrações científicas eurocêntricas, passando a adotar a ancestralidade da diáspora africana para o desafio político-conceitual de interseccionalidade. Ela entende que: 


\begin{abstract}
A interseccionalidade visa dar instrumentalidade teórico-metodológico acerca da inseparabilidade estrutural do racismo, capitalismo e cisheteropatriarcado - produtores de avenidas identitárias em que mulheres negras são repetidas vezes atingidas pelo cruzamento e sobreposição de gênero, raça e classe, modernos aparatos coloniais (AKOTIRENE, 2019, p. 19)
\end{abstract}

Parte da concepção de que há uma matriz conceitual moderna que possui relações de poder que manifestam a multiplicidade de estruturas dinâmicas que requerem dos grupos vitimados: " 1 . Instrumentalidade conceitual de raça, classe, nação e gênero; 2 . sensibilidade interpretativa dos efeitos identitários; 3. atenção global para a matriz colonial moderna, evitando desvio analítico para apenas um eixo de opressão" (AKOTIRENE, 2019, p. 20).

Desse modo, o uso da interseccionalidade como um recurso de ensino e aprendizagem propõe o uso de saberes que oportunizam ao professor interagir diferentes avenidas identitárias para compreender a constituição de sistemas de opressão. Não se busca a criação de privilégios de agrupamentos sociais subalternos, mas o reconhecimento identitário das diferenças que trazem para a sociedade brasileira. As narrativas advindas de suas diferenças propõem outras abordagens de ensino e aprendizagem que valorizam a pluralidade dos povos e suas participações na constituição da ideia de povo brasileiro pluralizado.

Propõe, então, reconhecer que a diferença é elemento que diversifica a presença de estudantes nas escolas públicas brasileiras. Traz, com isso, possibilidades outras para o planejamento de ensino e aprendizagem, sendo a interseccionalidade uma forma de propor, no âmbito de diferentes áreas específicas, a condução de saberes plurais tanto para estudantes quanto para os/as professores/as.

\title{
Analise e interpretação dos dados
}

No primeiro semestre de execução do projeto de pesquisa (1오mestre de 2020), realizou-se o primeiro levantamento do estado da arte. $\mathrm{Na}$ plataforma do IBICT, a busca contou com a associação dos descritores: interseccionalidade e saberes docentes, e o levantamento proposto focou-se nas pesquisas de diferentes áreas de licenciaturas, distribuídas pelos programas de pós-graduação brasileiros. Desse levantamento, obteve-se o seguinte mapeamento: 
SILVA, F. G. O.

Quadro 1: Pesquisas sobre interseccionalidade e saberes docentes

\begin{tabular}{|c|c|c|c|c|c|}
\hline ANO & IES & GRAU & TíTULO & ÁREA & AUTORIA \\
\hline 2003 & UFRGS & D & $\begin{array}{l}\text { Competências docentes } \\
\text { para a prática pedagógico- } \\
\text { musical no ensino } \\
\text { fundamental e médio: } \\
\text { visão dos professores de } \\
\text { música }\end{array}$ & Música & $\begin{array}{l}\text { Daniela } \\
\text { Dotto } \\
\text { Machado }\end{array}$ \\
\hline 2005 & UFRGS & D & $\begin{array}{l}\text { Materiais didáticos nas } \\
\text { aulas de música: um } \\
\text { survey com professores } \\
\text { da Rede Municipal de } \\
\text { Ensino de Porto Alegre - } \\
\text { RS }\end{array}$ & Música & $\begin{array}{l}\text { Fernanda } \\
\text { de } \\
\text { Assis } \\
\text { Oliveira }\end{array}$ \\
\hline 2007 & UFRGS & D & $\begin{array}{l}\text { Música nas séries finais } \\
\text { do ensino fundamental } \\
\text { e no ensino médio: um } \\
\text { survey com professores } \\
\text { de arte/música de escolas } \\
\text { estaduais da região sul do } \\
\text { Rio Grande do Sul }\end{array}$ & Música & $\begin{array}{l}\text { Isabel } \\
\text { Bonat } \\
\text { Hirsch }\end{array}$ \\
\hline 2011 & UFSM & D & $\begin{array}{l}\text { Música no ensino } \\
\text { fundamental: A Lei } \\
\text { 11.769/08 e a situação de } \\
\text { escolas de Santa Maria/ } \\
\text { RS }\end{array}$ & Educação & $\begin{array}{l}\text { Laila Azize } \\
\text { Souto } \\
\text { Ahmad }\end{array}$ \\
\hline 2016 & UFSC & D & $\begin{array}{l}\text { Vozes das mulheres } \\
\text { negras cotistas da } \\
\text { Universidade Federal de } \\
\text { Santa Catarina (2010- } \\
\text { 2014) }\end{array}$ & Educação & $\begin{array}{c}\text { Ione Ribeiro } \\
\text { Valle }\end{array}$ \\
\hline 2017 & UFPB & D & $\begin{array}{l}\text { Os livros de ciências: } \\
\text { saúde e doenças } \\
\text { prevalentes da população } \\
\text { negra em uma possível } \\
\text { articulação com a Lei } \\
10.639 / 2003\end{array}$ & Educação & $\begin{array}{c}\text { Débora } \\
\text { Michele } \\
\text { Sales de } \\
\text { Lima }\end{array}$ \\
\hline
\end{tabular}




\begin{tabular}{|c|c|c|c|c|c|}
\hline 2017 & PUC RIO & D & $\begin{array}{l}\text { Por um sentir crítico: } \\
\text { um olhar feminista } \\
\text { interseccional sobre } \\
\text { a socioconstrução de } \\
\text { identidades sociais de } \\
\text { gênero, raça/etnia e } \\
\text { classe de professoras de } \\
\text { línguas }\end{array}$ & Letras & $\begin{array}{l}\text { Thais } \\
\text { Regina } \\
\text { Santos } \\
\text { Borges }\end{array}$ \\
\hline 2018 & UFRGS & $D$ & $\begin{array}{l}\text { As Marias da Conceição: } \\
\text { por um ensino de história } \\
\text { situado, decolonial e } \\
\text { interseccional }\end{array}$ & História & $\begin{array}{l}\text { Carla de } \\
\text { Moura }\end{array}$ \\
\hline 2018 & UNISINOS & $D$ & $\begin{array}{l}\text { Entre a política e } \\
\text { o movimento: as } \\
\text { concepções e as práticas } \\
\text { políticas de mulheres } \\
\text { negras no Morro da } \\
\text { Polícia }\end{array}$ & $\begin{array}{l}\text { Ciências } \\
\text { Sociais }\end{array}$ & $\begin{array}{c}\text { Thais da } \\
\text { Rosa } \\
\text { Alves }\end{array}$ \\
\hline 2018 & UNB & D & $\begin{array}{l}\text { Jovens negras no } \\
\text { ensino médio público } \\
\text { e privado no DF: um } \\
\text { estudo comparado e } \\
\text { interseccional sobre suas } \\
\text { vivências e percepções do } \\
\text { racismo }\end{array}$ & Educação & $\begin{array}{l}\text { Éllen } \\
\text { Daiane } \\
\text { Cintra }\end{array}$ \\
\hline 2018 & UFF & $D$ & $\begin{array}{l}\text { Uma análise feminista da } \\
\text { construção de gênero em } \\
\text { livros didáticos de inglês } \\
\text { aprovados pelo PNLD } \\
2014\end{array}$ & Letras & $\begin{array}{c}\text { Maria } \\
\text { Gabriella } \\
\text { Mayworm } \\
\text { de Castro }\end{array}$ \\
\hline 2019 & UFSCAR & $\mathrm{T}$ & $\begin{array}{l}\text { "Como é no seu país?" } \\
\text { Estudo autoetnográfico } \\
\text { de uma prática } \\
\text { pedagógica em Português } \\
\text { Língua de Acolhimento } \\
\text { para mulheres migrantes } \\
\text { no Brasil: implicações } \\
\text { para a formação de } \\
\text { professores }\end{array}$ & Letras & $\begin{array}{c}\text { Eleonora } \\
\text { Bambozzi } \\
\text { Bottura }\end{array}$ \\
\hline
\end{tabular}




\begin{tabular}{|l|l|l|l|l|l|}
\hline 2019 & PUC RIO & T & $\begin{array}{l}\text { Entre bordas e fronteiras: } \\
\text { gênero, política e } \\
\text { interseccionalidade no } \\
\text { funk }\end{array}$ & $\begin{array}{c}\text { Ciências } \\
\text { Sociais }\end{array}$ & $\begin{array}{c}\text { Mariana } \\
\text { Gomes } \\
\text { Caetano }\end{array}$ \\
\hline UNESP & D & $\begin{array}{l}\text { Jovens negras e a sala } \\
\text { de aula: caminhos } \\
\text { para promor o o } \\
\text { reconhecimento da } \\
\text { negritude feminina } \\
\text { por meio do ensino de } \\
\text { sociologia }\end{array}$ & Sociologia & $\begin{array}{c}\text { Mariana } \\
\text { Alves } \\
\text { de Sousa }\end{array}$ \\
\hline
\end{tabular}

Fonte: Elaborado pelo autor, 2020.

É válido considerar que não foram registradas as pesquisas anteriores à plataforma Sucupira. Foram encontradas 14 (catorze) produções, sendo 12 (doze) dissertações e 2 (duas) teses. Na análise dos dados, observou-se que os estudos se iniciam, em 2003, e possuem dois intervalos de produções, sendo o primeiro entre 2007-2011, e o segundo entre 2011 e 2016. Em relação às regiões, nota-se em forma decrescente: 7 (sete) pesquisas localizadas no Sul, 5 (cinco) no Sudeste, 1 (uma) no Nordeste e 1 (uma) no Centro-oeste. E, no que se refere às áreas encontradas, registrou-se:

1. Ciências Humanas: 4 (quatro) pesquisas na área da Educação, 1 (uma) em História e 1 (uma) em Sociologia;

2. Ciências Sociais aplicadas: 2 (duas) em Ciências Sociais;

3. Linguística, Letras e Artes: 3 (três) de Letras e 3 (três) de Música.

A partir da leitura dos resumos das produções encontradas, buscou-se entender se o estudo propôs o uso da interseccionalidade como um recurso de ensino e aprendizagem por meio dos saberes docentes. A área de Linguística foi a primeira que o filtro descritivo apontou o uso da interseccionalidade no ensino de música, entretanto, é preciso destacar que algumas autorias não trataram da questão da interseccionalidade como um recurso pedagógico. Registrou-se, com a leitura dos resumos, que 4 (quatro) pesquisas abordam a educação musical e usam a ideia dos surveys de desenho interseccional utilizados como recursos metodológicos para aplicação da pesquisa e não no ensino de música, sendo elas: Machado (2003); Oliveira (2005); Hirsch (2007); Ahmad (2011). 
Foram encontradas 5 (quatro) pesquisas que abordam a interseccionalidade, porém, como uma ferramenta para entender a interação de avenidas identitárias de raça e gênero de mulheres das classes populares, e professoras de línguas acerca de suas culturas, como é o caso de Valle (2016); Borges (2017); Alves (2018); Cintra (2018) e Caetano (2019). Tais pesquisas tratam do assunto da interseccionalidade, mas não abordam o seu uso por meio dos saberes docentes.

Importa destacar que 5 (cinco) pesquisas trataram da interseccionalidade como uma ferramenta pedagógica para o ensino de Biologia, História, Línguas e Sociologia. Faz entender que o uso da interseccionalidade como parte dos saberes docentes despontaram mais recentemente no âmbito das pesquisas, datando-se do ano de 2017. Por encontrar um terreno farto de descrição, nas próximas linhas são apontadas as possibilidades de uso da interseccionalidade encontradas nas propostas de pesquisa de Lima (2017); Moura (2018); Castro (2018); Bottura (2019) e Sousa (2020).

Enfaticamente, a intersecção é tratada como uma visão em Lima (2017), nos saberes necessários para o ensino de biologia. A autora avalia os livros didáticos de Ciências do 8 o ano do Ensino Fundamental, analisando, assim, a articulação das doenças prevalecentes que atingem a população negra. Lima (2017) destacou que, mesmo que a legislação, em especial a Lei no. $10.639 / 2003$, reforce que os estudos afrocêntricos precisam compor diferentes disciplinas, ainda é notória a não contemplação de assuntos pertinentes à legislação. Notadamente, a autora afirma que os assuntos pertinentes à legislação entram com no campo das Artes e da História, desqualificando a área do ensino de biologia de um lugar de discussão.

No âmbito do ensino de História, Carla de Moura (2018) quis inovar suas práticas de ensino. Para isso, resolveu realizar um experimento que considerou pedagógico-teórico-metodológico a partir do conceito do ensino de História situado que é entrelaçado à perspectiva da interseccionalidade. Com sua ação pedagógica na área de História, enfatizou o assunto da produção da comunidade por meio da construção de materiais audiovisuais com a autoria de alunos/alunas do 8 o ano do ensino fundamental. O objetivo foi propor aos/as alunos/as acessar memórias de construção do espaço, fontes orais e significação de patrimônio, onde foram levados/as a fazer uma análise interseccional sobre os marcadores sociais de raça, gênero e classe que operam na constituição de mulheres da Vila Maria da Conceição.

Observou que, a partir da sua estratégia de ensino sob o uso da interseccionalidade, das pedagogias decoloniais, as pedagogias da encruzilhada 
e a ideia de lugar de fala; os/as alunos/as puderam empoderar-se de ancestralidade, por meio das narrativas acessadas e, com isso, sentirem-se parte dos saberes construídos na comunidade da qual fazem parte.

Castro (2018), por sua vez, buscou relacionar gênero, identidade, escola e Estado a partir do livro didático de língua inglesa, para estudantes do 9 o ano do Ensino Fundamental. Para isso, contou com perspectivas feministas radicais, pensamento decolonial e diferentes políticas públicas curriculares. A autora conclui, a partir da problematização de imagens, textos e atividades de línguas, que os livros didáticos precisam avançar na proposição de intertextualidades socialmente relevantes e em constante diálogos com o real, evitando, assim, reproduzir lógicas de exclusões históricas.

Bottura (2019) também faz uma análise da interseccionalidade como uma ferramenta metodológica no ensino de línguas para acolher mulheres imigrantes, refugiadas e em situação de vulnerabilidade social no Brasil. Conforme o posicionamento autoetnográfico e reflexivo de sua condição docente, de um programa de língua de acolhimento, Bottura (2019) observou articulações com a categoria raça e gênero como elementos que trazem requisições para o ensino de línguas, tornando necessário abordá-lo sob a perspectiva interseccional.

Sousa (2020), no contexto do ensino de sociologia, encontra um terreno farto de problematizações para que o reconhecimento da identidade feminina negra não seja tardio como observou em juventudes negras do Ensino Médio. Acredita que o tratamento interseccional à questão de raça e de gênero precisa fazer parte também dos livros didáticos, evitando a invisibilidade teórica e conceitual. Além disso, conclui ser necessária a adoção de práticas engajadas na Lei no. 10.639/2003, por propor a construção de uma imagem afrocêntrica, diferenciada das que são criadas na sociedade brasileira.

Nesse sentido, a interseccionalidade propõe conferir visibilidade ao cruzamento de diferentes demarcadores sociais para construir formas de problematizar as desigualdades vividas por grupos minoritários ou que convivem com uma servidão voluntária para a permanência nos locais formatados à norma.

\section{Considerações Finais}

Acredita-se que o ensaio, aqui feito, não é um aprofundamento teórico do assunto, mas as linhas iniciais de um primeiro levantamento realizado do projeto de pesquisa. Englobaram-se as práticas realizados pelos/as professores/as no processo de planejamento, execução e avaliação de estudantes no conceito 
dos saberes docentes eleitos para o ato de ensinar. Com tal ideia, objetivou-se entender esse ato como vinculado ao real, o que oportuniza que nos descolemos da ilusão de que existem alunos/as no formato decididamente tradicional: parados/as, enquanto nós, professores/as, depositamos o conhecimento colonialmente creditado indispensável para um processo de submissão consentida.

Ao contrário, pensou-se numa proposta de abordagem que conseguisse problematizar o ato de ensino e, consequentemente, o de aprender, a partir de questões advindas do terreno de morada, de vida, de produção subjetiva e identitária dos/das estudantes. A abordagem da interseccionalidade possibilita efetivar uma ação pedagógica em que aprender como os corpos transitam nas vias de opressão, interagem e produzem formas de submissão ou de resistência representa o real objetivo desse enfoque.

A interseccionalidade pode ser vista como uma ferramenta política, de resistência, de posicionamento em desfavor da manutenção de processos eurocêntricos que encontram no ato de ensinar o adestramento de corpos, o apagamento das diferenças e o silenciamento da liberdade. Pensou-se no ato de ensinar, porque, independentemente de forças externas dos organismos que gerenciam a educação (secretarias, coordenadorias, diretorias regionais...), o/a professor/a será o/a único/a a ser responsabilizado/a pelo que não deu certo.

Por conta disso, o discurso de pragmatismo pedagógico e eficiência pedagógica invisibiliza o ambiente escolar e a sala de aula da potência, entusiasmo e curiosidade epistemológica. É preciso propor ao ato de ensinar a vinculação com o sujeito que compõe os bancos escolares e, por acreditar que isso é teórica e politicamente possível, que seja proposto um estudo, na área de educação, com o uso de uma metodologia capaz de movimentar outros possíveis no ambiente escolar, causando, provocando as disciplinas escolares.

Trabalhar com as diferenças, com a perspectiva da liberdade e de questões ético-políticas, como se viu no item análise e interpretação dos dados, fica a cargo de disciplinas como: Arte, Filosofia, História, Ciências Sociais, Sociologia; eximindo as outras disciplinas de abordarem o assunto das diferenças sob a ótica da interseccionalidade.

É possível abordar questões inerentes a alguns grupos subalternos no contexto da disciplina de matemática, física e química. Para isso, as questões socioculturais que afetam os/as estudantes precisam ser compreendidas, para que os saberes docentes sejam movimentados e engajados no contexto de questões sociais, ambientais, culturais, econômicas que precarizam vidas para ensinar direito à educação, diferença e legitimidade existencial. 


\section{Referências}

AKOTIRENE, C. Interseccionalidade. São Paulo: Polén, 2019.

BORGES, C. Saberes docentes: diferentes tipologias e classificações de um campo de pesquisa. Educação \& Sociedade, Campinas, v. 22, n. 74. 2001. p.59-76. Disponível em: https://www.scielo.br/pdf/es/v22n74/a05v2274. pdf. Acesso em: 12 mai. 2020.

BOTTURA; E. B. "Como é no seu país?" Estudo autoetnográfico de uma prática pedagógica em Português Língua de Acolhimento para mulheres migrantes no Brasil: implicações para a formação de professores. 2019. 247f. Tese (Doutorado em Linguística) - Universidade Federal de São Carlos, São Carlos, 2019.

CANDAU, V. M. Direitos humanos, educação e interculturalidade: as tensões entre igualdade e diferença. Revista Brasileira de Educação, Rio de Janeiro, v. 13, n. 37, Jan./Apr. 2008. Disponível em: https://www.scielo.br/pdf/rbedu/ v13n37/05.pdf. Acesso em: 15 mai. 2020.

CASTRO, M. G. M. de. Uma análise feminista da construção de gênero em livros didáticos de inglês aprovados pelo PNLD 2014. 2016. 116f. Dissertação (Mestrado em Estudos de Linguagem) - Universidade Federal Fluminense, Niterói, 2016.

CORAZZA, S. O que quer um currículo? Pesquisas pós-críticas em Educação. Petrópolis: Vozes, 2001.

CREENSHAW, K. Documento para o encontro de especialistas em aspectos da discriminação racial relativas ao gênero. Estudos Feministas, Florianópolis, n. 10, v. 1, Jan. 2002. p. 177-188. Disponível em: https://www.scielo.br/pdf/ref/ v10n1/11636.pdf. Acesso em: 01 mai. 2020.

FERREIRA, N. S. de A. As pesquisas denominadas "Estado da arte". Educação \& Sociedade, Campinas, v. 23, n. 79, Ago. 2002. p. 257-272. Disponível em: https://www.scielo.br/pdf/es/v23n79/10857.pdf. Acesso em: 01 mai. 2020.

FREIRE; P. Pedagogia da autonomia: saberes necessários à prática educativa. São Paulo: Paz e Terra, 1996.

LIMA, D. N. S. de. Os livros de ciências: saúde e doenças prevalentes da população negra em uma possível articulação com a Lei 10.639/2003. 2017. 140f. Dissertação (Mestrado em Educação) - Universidade Federal da Paraíba, João Pessoa, 2017. 
LIMA, T. C. S. de; MIOTO, R. C. T. Procedimentos metodológicos na construção do conhecimento científico: a pesquisa bibliográfica. Revista Katálysis, Florianópolis, v. 10, n. esp. 2007. p. 37-45. Disponível em: https://www.scielo.br/ pdf/rk/v10nspe/a0410spe.pdf. Acesso em: 22 mai. 2020.

MICHAELIS. Dicionário brasileiro da Língua Portuguesa. Editora Melhoramentos: UOL, 2020. Disponível em: https://michaelis.uol.com.br/. Acesso em: 02 mai. 2020.

MOURA, C. de. As Marias da Conceição: por um ensino de história situado, decolonial e interseccional. 2018. 193f. Dissertação (Mestrado em Ensino de História) - Universidade Federal do Rio Grande do Sul, Porto Alegre, 2018.

NUNES, C. M. F. Saberes docentes e formação profissional de professores: um breve panorama na pesquisa brasileira. Educação \& Sociedade, Campinas, n. 74. 2001. p. 27-42. Disponível: https://www.scielo.br/pdf/es/v22n74/ a03v2274. Acesso em: 02 mai. 2020.

PARAISO, M. A. Pesquisas pós-críticas em educação no Brasil: esboço de um mapa. Cadernos de Pesquisa, São Paulo, v. 34, n. 122, maio/ago. 2004. p. 283303. Disponível em: https://www.scielo.br/pdf/cp/v34n122/22506.pdf. Acesso em: 20 mai. 2020.

PISCITELLI, Adriana. Interseccionalidade, categorias de articulação e experiências de migrantes brasileiras. Sociedade e Cultura, v.11, n.2, jul/dez, 2008, p. 263-274.

ROMANOWSKI; J. P; ENS, R. T. As pesquisas denominadas do tipo "estado da arte" em educação. Diálogo Educacional, Curitiba, v. 6, n. 19, set./dez. 2006. p. 37-50. Disponível em: https://periodicos.pucpr.br/index.php/dialogoeducacional/article/view/24176. Acesso em: 12 mai. 2020.

SAVIANI, D. Os saberes implicados na formação do educador. In: BICUDO, M. A; SILVA JUNIOR, C. A. (Orgs.). Formação do educador: dever do Estado, tarefa da Universidade. São Paulo: Unesp, 1996.

SILVA, T. T. A produção social da identidade e da diferença. In: SILVA, T. T.; HALL, S.; WOODWARD, K. (orgs). Identidade e diferença: a perspectiva dos estudos culturais. Rio de Janeiro: Editora Vozes, 2000. p. 73-102.

SOUSA, M. A. de. Jovens negras e a sala de aula: caminhos para promover o reconhecimento da negritude feminina por meio do ensino de sociologia. 2020. 196f. Dissertação (Mestrado em Sociologia) - Universidade Estadual Paulista "Júlio de Mesquita Filho", Marília, 2020. 
TARDIF, M. Saberes docentes e formação profissional. Petrópolis: Vozes, 2002.

YOUTUBE. Vídeo completo: a reunião de Bolsonaro com ministros em 22 de abril. Disponível em: https://www.youtube.com/watch?v=nfgv7DLdCqA. Acesso em: 01 jun. 2020.

Data de recebimento: 02.06 .2020

Data de aceite: 06.06.2021 